\title{
Species delimitation in the presence of strong incomplete lineage sorting and hybridization: Lessons from Ophioderma (Ophiuroidea: Echinodermata)
}

\author{
Alexandra Anh-Thu Weber ${ }^{\mathrm{a}, \mathrm{b}, *}$, Sabine Stöhr ${ }^{\mathrm{c}}$, Anne Chenuil ${ }^{\mathrm{a}}$ \\ ${ }^{a}$ Aix Marseille Univ, Avignon Université, CNRS, IRD, IMBE, Marseille, France \\ ${ }^{\mathrm{b}}$ Zoological Institute, University of Basel, Vesalgasse 1, 4051 Basel, Switzerland \\ ${ }^{c}$ Swedish Museum of Natural History, Department of Zoology, Box 50007, 10405 Stockholm, Sweden
}

\section{A R T I C L E I N F O}

\section{Keywords:}

Approximate Bayesian Computation

Multi-species coalescent

Discriminant Analysis of Principal Components

Cryptic species

Echinoderms

Ophiuroidea

\begin{abstract}
A B S T R A C T
Accurate species delimitation is essential to properly assess biodiversity, but also for management and conservation purposes. Yet, it is not always trivial to accurately define species boundaries in closely related species due to incomplete lineage sorting. Additional difficulties may be caused by hybridization, now evidenced as a frequent phenomenon. The brittle star cryptic species complex Ophioderma longicauda encompasses six mitochondrial lineages, including broadcast spawners and internal brooders, yet the actual species boundaries are unknown. Here, we combined three methods to delimit species in the Ophioderma longicauda complex and to infer its divergence history: (i) unsupervised species discovery based on multilocus genotypes; (ii) divergence time estimation using the multi-species coalescent; (iii) divergence scenario testing (including gene flow) using Approximate Bayesian Computation (ABC) methods. 30 sequence markers (transcriptome-based, mitochondrial or non-coding) for $89 \mathrm{O}$. longicauda and outgroup individuals were used. First, multivariate analyses revealed six genetic clusters, which globally corresponded to the mitochondrial lineages, yet with many exceptions, suggesting ancient hybridization events and challenging traditional mitochondrial barcoding approaches. Second, multi-species coalescent-based analyses confirmed the occurrence of six species and provided divergence time estimates, but the sole use of this method failed to accurately delimit species, highlighting the power of multilocus genotype clustering to delimit recently diverged species. Finally, Approximate Bayesian Computation showed that the most like $y$ scenario involves hybridization between brooders and broadcasters. Our study shows that despite strong incomplete lineage sorting and past hybridization, accurate species delimitation in Ophioderma was possible using a combination of complementary methods. We propose that these methods, especially multilocus genotype clustering, may be useful to resolve other complex speciation histories.
\end{abstract}

\section{Introduction}

Accurate species delimitation and description is essential to properly assess biodiversity, but also for management and conservation purposes (Agapow et al., 2004; De Queiroz, 2007). Historically and still nowadays, the vast majority of species are delimited using morphological characters, based on descriptions of type specimens for each nominal species, uniquely identified by Latinized names in the binominal nomenclature codified first by Linnaeus in the 18th century (for zoology (Linnaeus, 1758)). However, genetically isolated groups of morphologically indistinguishable individuals were detected in many nominal species during the last decades, owing to the use of genetic markers in population genetic studies (Bickford et al., 2007; Knowlton, 1993; Pfenninger and Schwenk, 2007). Such groups are often called cryptic species (Struck et al., 2018), which are widely spread and homogeneously distributed across the metazoan biodiversity (Pfenninger and Schwenk, 2007). The occurrence of cryptic species can be explained with several main factors: (i) recent species divergence (i.e. morphological differences may not have evolved yet); (ii) parallelism or convergence (i.e. cryptic species are not closely related but morphologically similar due to selection pressures); (iii) morphological stasis (i.e. decreased morphological disparity compared to genetic divergence) (Struck et al., 2018)). Cryptic species were first identified by diagnostic codominant markers such as allozymes (e.g. Knowlton, 1993) and then, in most cases, by single mitochondrial markers (e.g. Hebert et al., 2004). Even presently, they are rarely identified using a combination of several molecular markers and phenotypic data (Struck et al., 2018).

Due to their lower effective size, genetic markers from haploid genomes are more affected by genetic drift and thus reach reciprocal

\footnotetext{
* Corresponding author at: Marine invertebrates, Museums Victoria, GPO Box 666, Melbourne, VIC 3001, Australia.

E-mail addresses: aweber@museum.vic.gov.au (A.A.-T. Weber), sabine.stohr@nrm.se (S. Stöhr).
} 
monophyly (i.e. alleles of distinct species form separate monophyletic groups) more rapidly than markers from nuclear genomes after species divergence. This explains their power to detect recently diverged cryptic species and their wide use for biodiversity barcoding (Bucklin et al., 2011). However, absence of gene flow among groups of individuals cannot be established on the basis of markers from single haploid genomes since past bottlenecks or selective sweeps may generate patterns of divergent groups of closely related haplotypes within a panmictic entity (i.e. a group of randomly mating individuals). In addition, mitochondrial markers only reflect the history of maternal lineages, which can be significantly different from the species history if males and females display different dispersal behaviors. Finally, past hybridization events can be misleading for species identification based on mitochondrial barcodes, as mitochondrial lineages can be incongruent with the species history (Currat et al., 2008; Melo-Ferreira et al., 2014).

Finding independent markers confirming mitochondrial divergence may be difficult for recently diverged species, especially in non-model organisms with scarce to non-existing available genomic data. The most intuitive and popular approach for cryptic species delimitation consists of finding independent markers displaying reciprocal monophyly that are congruently associated within individuals (in linkage disequilibrium) (De Queiroz, 2007; Mkare et al., 2017). However, confirming absence of gene flow should not rely on finding reciprocal monophyly in independent markers (Zhang et al., 2011) for the following reasons: (i) Recently diverged species, especially when their reproductive isolation is conferred by a single locus or few loci, rarely display reciprocally monophyletic markers, as most loci are either monomorphic or display shared polymorphism among species (i.e. incomplete lineage sorting). (ii) Recently diverged species may display diagnostic markers but not reciprocal monophyly when diagnosticity resulted from genetic drift (allele loss) but mutation events were not sufficient to create a pattern of reciprocal monophyly. (iii) There are other means to establish absence of gene flow using a set of independent genetic markers (e.g. the diagnosticity of a single Mendelian marker is sufficient, and see approaches based on multilocus genotype developed below).

Various methods (reviewed in Carstens et al., (2013)) propose to delimit species using nucleotide sequences from several markers. Some of these methods are based on divergence levels or consider ratio of within-group and between-group diversity to delimit species (e.g. the automatic barcoding gap discovery ABGD, (Puillandre et al., 2012). Although they provide powerful tools to propose primary species hypotheses for large datasets (Ratnasingham and Hebert, 2007), such approaches cannot prove the absence of gene flow and often depend on arbitrary thresholds or assumptions such as constant effective sizes among ancestor and daughter species. The multispecies coalescent theory (Fujita et al., 2012; Yang and Rannala, 2010) provides a statistical framework to model the coalescence of multiple markers during genetic isolation of groups of individuals. Bayesian methods applied to the multispecies coalescent allow establishing the probability of species partitions and phylogenies for a sample of allele sequences from various individuals (Rannala, 2015; Yang and Rannala, 2010) and the most recent development of this method, implemented in the software BPP (Yang, 2015), allows the joint inference of species (or lineage) delimitation and species phylogeny (Rannala and Yang, 2017; Yang and Rannala, 2014). However, despite these qualities and being able to handle some degree of Incomplete Lineage Sorting (ILS) (Carstens et al., 2007), the efficiency of these methods depend for a large part on the accumulation of mutations since species separation, and thus can only delimit entities isolated long enough (Rannala, 2015). By contrast, methods based on multilocus genotypes (e.g. Structure (Falush et al., 2003), Structurama (Huelsenbeck et al., 2011), DAPC (Jombart et al., 2010), although rarely used for species delimitation, can potentially reveal absence of gene flow after a single generation as they do not rely on information on allele relationships, like sequences, but use multilocus genotypes for each individual. In addition, they provide a fast and unbiased way of finding genetically separated entities, as they do not rely on a priori knowledge on individual grouping.

Even though much progress has been made in species tree estimation methods, the use of species trees implies that speciation is represented as a dichotomic process. Yet, there is increasing evidence for the role of hybridization and reticulate evolution in or after speciation (Abbott et al., 2013, 2016; Lamichhaney et al., 2017; Meier et al., 2017). Current species discovery and delimitation methods do not allow for testing such cases, but Approximate Bayesian Computation $(\mathrm{ABC})$ provides powerful methods allowing to do so (Csilléry et al., 2010; Lopes and Beaumont, 2010), with the simultaneous testing of several divergence scenarios (with or without hybridization) and estimation of demographic parameters (e.g. divergence times, effective population sizes, migration rates). These methods are computationally efficient, especially when using a small (tens or hundreds) number of loci, as they use simulated datasets for which several summary statistics are compared to the original dataset (instead of likelihood computations). Thus, information rich datasets such as sequence genotypes at tens of loci in a hundred individuals can be exploited using ABC.

Brittle stars (Ophiuroidea) encompass a large number of cryptic species (e.g. Barboza et al., 2015; Baric and Sturmbauer, 1999; Boissin et al., 2017, 2008; Heimeier et al., 2010; Hoareau et al., 2013; Hunter and Halanych, 2008; Muths et al., 2009, 2006; Naughton et al., 2014; Pérez-Portela et al., 2013; Sponer and Roy, 2002; Stöhr and Muths, 2010; Taboada and Pérez-Portela, 2016). The Ophioderma longicauda (Bruzelius, 1805) species complex encompasses six mitochondrial lineages and at least two sympatric biological species with contrasting reproductive strategies, namely the broadcast spawners C3 and the internal brooders $\mathrm{C} 5$, differing in reproductive timing, morphology, ecology and genetics (Boissin et al., 2011; Stöhr et al., 2009; Weber et al., 2015, 2014, 2013). Yet, the species relationships among all mitochondrial lineages across the whole $O$. longicauda distribution remain unclear.

We used 30 sequence markers to delimit species and infer divergence history of this complex of cryptic species using a combination of three methods: (i) unsupervised species discovery using multilocus genotypes; (ii) confirmation of lineage genetic isolation and divergence time estimates using the multi-species coalescent; (iii) divergence scenario testing using $\mathrm{ABC}$. We found that combining all three methods that use different properties of the data provides complementary information such as number of species, among species relationships, divergence time, effective population size and gene flow estimates to best represent complex speciation history. Furthermore, the use of multilocus genotypes performed better than the multispecies coalescent to delimit recently genetically isolated clusters.

\section{Material and methods}

\subsection{Sampling, DNA extraction and marker development}

89 individuals including the six $O$. longicauda mitochondrial lineages (L1-L6) sampled across the whole $O$. longicauda distribution and three outgroup species (Ophioderma teres (Lyman, 1860), Ophioderma cinerea (Müller \& Troschel, 1842) and Ophioderma phoenia (H.L. Clark, 1918)) were used in this study (Table 1, Table S1). Ophioderma outgroups were used to estimate divergence times of the $O$. longicauda species complex, the latter occurring in the North-East Atlantic Ocean and in the Mediterranean Sea (Fig. 1). Indeed, the species O. teres (Eastern Pacific Ocean), O. phoenia and O. cinerea (West Atlantic Ocean) are geminate pairs that speciated after the closing of the Isthmus of Panama, so the divergence between these species pairs (O. teres -O. phoenia or O. teres -O.cinerea) is at least 2.8 Mya (Lessios, 2008). DNA was extracted with MN-Tissue Kit (Macherey-Nagel) using an epimotion robot (Eppendorf) following the protocol of Ribout and Carpentieri (2013), and eluted in $200 \mu \mathrm{l}$ of sterile water. Extracted DNA 
Table 1

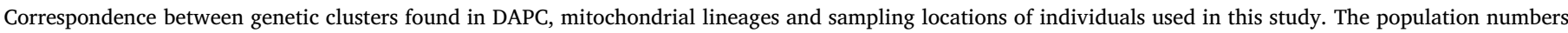

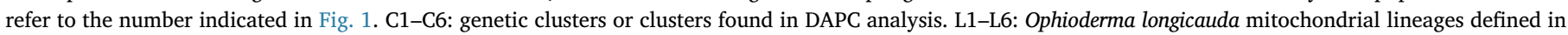
Boissin et al. (2011). Congruent: congruence between mitochondrial lineage and nuclear data (genetic cluster).

\begin{tabular}{|c|c|c|c|c|c|}
\hline Locality & Number of individuals & Population number & Genetic cluster & Mitochondrial lineage & Congruent \\
\hline Thiouriba/Cap Vert Peninsula, Dakar, Senegal & 4 & $1 \mathrm{a}$ & $\mathrm{C} 1$ & L6 & Yes \\
\hline Cap Manuel, Dakar, Senegal & 2 & $1 b$ & $\mathrm{C} 2$ & L5 & Yes \\
\hline Madelene Island, Dakar, Senegal & 2 & $1 c$ & $\mathrm{C} 2$ & L5 & Yes \\
\hline Gorée Island, Dakar, Senegal & 6 & $1 \mathrm{~d}$ & $\mathrm{C} 2$ & L5 & Yes \\
\hline Teneriffe, Canary Islands & 1 & 2 & $\mathrm{C} 3$ & L5 & No \\
\hline Madeira, Portugal & 1 & 3 & $\mathrm{C} 3$ & L5 & No \\
\hline Algarve, Portugal & 7 & 4 & $\mathrm{C} 3$ & L1 & Yes \\
\hline Ceuta, Spain & 2 & 5 & $\mathrm{C} 3$ & L5 & No \\
\hline Tabarka, Tunisia & 5 & 6 & $\mathrm{C} 3$ & L1 & Yes \\
\hline Kelibia, Tunisia & 6 & 7 & $\mathrm{C} 4$ & L3b & Yes \\
\hline Monastir, Tunisia & 5 & 8 & $\mathrm{C} 4$ & L3b & Yes \\
\hline Agios Pavlos, Crete & 5 & 9 & $\mathrm{C} 3$ & L1 & Yes \\
\hline Agios Pavlos, Crete & 4 & 9 & C5 & L3 & Yes \\
\hline Symi island, Greece & 4 & 10 & $\mathrm{C} 3$ & L1 & Yes \\
\hline Symi island, Greece & 7 & 10 & C5 & L2 \& L3 & No \\
\hline Baths of Aphrodite, Cyprus & 5 & 11 & $\mathrm{C} 3$ & L1 & Yes \\
\hline Baths of Aphrodite, Cyprus & 5 & 11 & $\mathrm{C} 6$ & $\mathrm{~L} 4$ & Yes \\
\hline Ramkine, Lebanon & 1 & $12 \mathrm{a}$ & $\mathrm{C} 3$ & L1 & Yes \\
\hline Ramkine, Lebanon & 4 & $12 \mathrm{a}$ & $\mathrm{C} 6$ & $\mathrm{~L} 2$ & No \\
\hline Beirut \& Raoucheh, Lebanon & 2 & $12 \mathrm{~b}$ & C6 & $\mathrm{L} 4$ & Yes \\
\hline
\end{tabular}

was diluted 10x in sterile water prior to PCR and $1 \mu$ of DNA was used for PCR amplification. We used orthologous genes from transcriptomes of O. longicauda C3 and C5 (Weber et al., 2017), corresponding to mitochondrial lineages L1 and L3, respectively (Weber et al., 2015) to develop 55 primer pairs to test. The criteria for locus development were: (i) the locus should be polymorphic; (ii) in half of the loci, at least one diagnostic SNP between C3 and C5 should be present; (iii) the length of the PCR product should be $300-400 \mathrm{bp}$ (due to sequencing

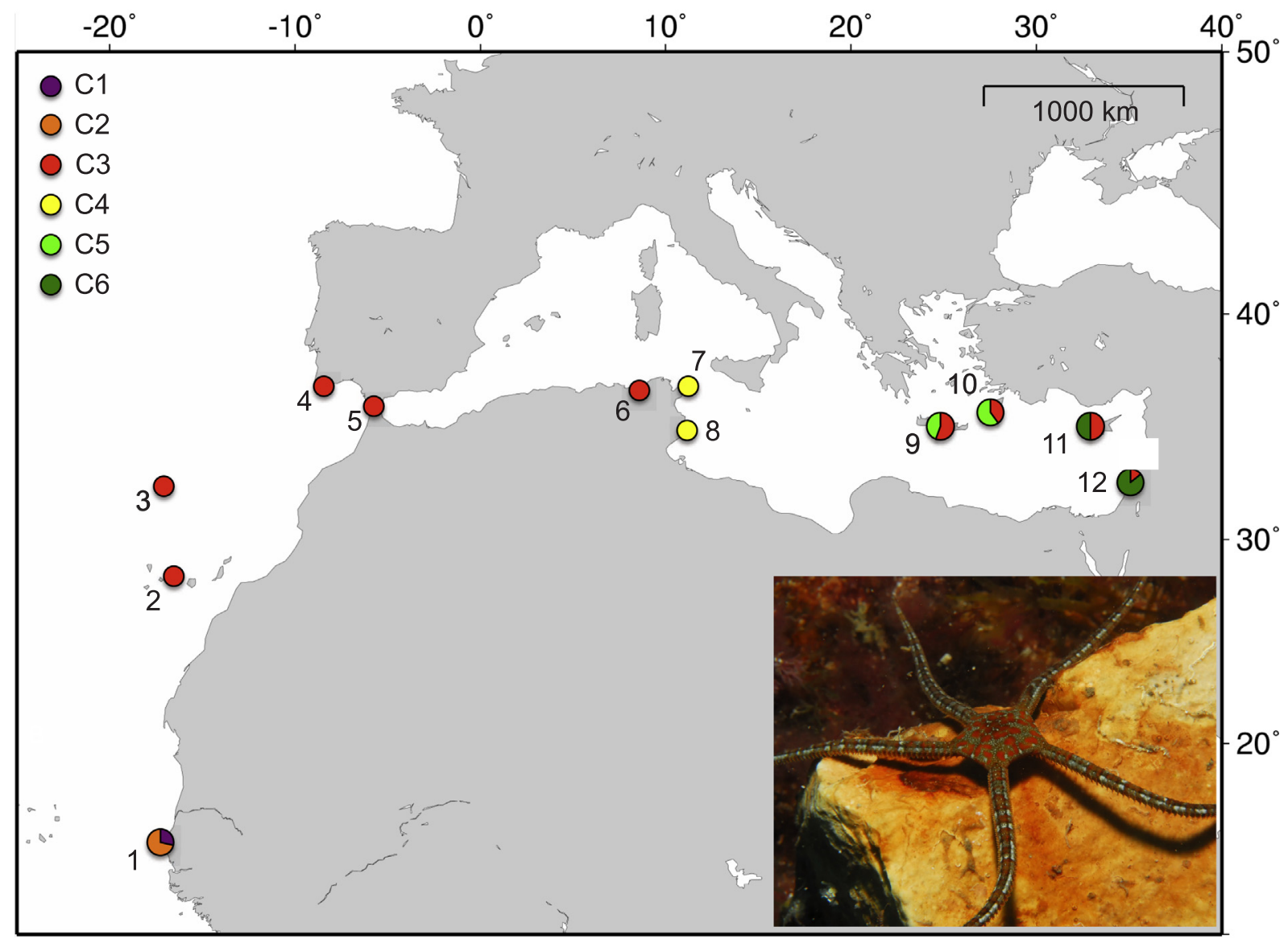

Fig. 1. Map of sampling localities with colors corresponding to genetic clusters found with DAPC. 1: Dakar, Senegal. 2: Tenerife, Canary Islands, Spain. 3: Madeira, Portugal. 4: Algarve, Portugal. 5: Ceuta, Spain. 6: Tabarka, Tunisia. 7: Kelibia, Tunisia. 8: Monastir, Tunisia. 9: Agios Pavlos, Crete, Greece. 10: Symi island, Greece. 11: Baths of Aphrodite, Cyprus. 12: Ramkine, Beirut and Raoucheh, Lebanon. A photograph of O. longicauda C3 from Marseilles, France, is displayed for illustration. Photo credit: Frédéric Zuberer. 
technology limitations). In addition, seven already existing loci were used, namely a mitochondrial locus (COI), ribosomal loci (ITS1, ITS2) and four EPIC loci, introns i21, i36, i50 and i54b (Chenuil et al., 2010; Gérard et al., 2013; Penant et al., 2013). Of the 55 exon-based loci tested, 16 amplified correctly in each lineage of $O$. longicauda. Furthermore, six out of seven existing loci amplified correctly. Finally, 22 loci were PCR amplified in the 89 specimens.

\subsection{Amplicon sequencing and dataset processing}

PCR products of different genes belonging to the same individual were pooled according to agarose gel quantification, i.e. quantities of PCR product were adjusted for pooling according to the band intensity on agarose gel. 96 Illumina libraries were then constructed using MiSeq Reagent Kits v2 (Illumina). Paired-end $(2 \times 250 \mathrm{pb})$ sequencing of the 96 libraries was performed on a single run of MiSeq Sequencing System (Illumina). Library preparation and subsequent sequencing were performed by the genomic platform Genotoul (www.genotoul.fr). About thirty millions raw reads were obtained after sequencing. For each library, Illumina adapters were trimmed, forward and reverse reads were assembled and demultiplexed by locus using the program MOTHUR $\mathrm{v}$ 1.31.2 (Schloss et al., 2009). On average, between 1000 and 10,000 reads were obtained per locus and per individual. Then, identical reads were clustered and the number of reads per locus and per individual was counted.

As the number of reads differed greatly between loci (less than 100 reads to more than 1000 reads), applying a fixed threshold to keep final sequences was not possible. In addition, five loci displayed paralogs (i.e. more than two sequences with high and similar number of reads displayed). For this reason, selecting the sequence displaying the highest number of reads could lead to incorrectly selecting and clustering paralogs. Therefore, for each of the 22 loci, the number of reads obtained for 5-10 individuals was manually checked to determine a threshold to apply to each individual per locus. One (for homozygous individuals) or two sequences (for heterozygous individuals) were kept per individual and per locus when paralogs were unambiguously absent, and up to ten sequences per individual and per locus were kept when paralogs were detected. Of the 22 loci, three could not be used due to a too low number of reads obtained after sequence cleaning. A total of 18 loci were obtained, and five of them displayed paralogs $(11,915,50,183,68,241,80,488$ and 109,458). Linkage equilibrium was tested among all paralogs from the same locus using Genetix (Belkhir et al., 2004). All paralogs displayed linkage equilibrium (i.e. the markers were independent) except three paralogs that displayed statistically significant linkage disequilibrium (50183-II, 50183-III and 50183-IV; $\mathrm{p}<0.05$ ). Therefore, these three paralogs were concatenated and considered as a single marker for all subsequent analyses. Finally, a total of 30 markers were available for further analyses (Table S2).

\subsection{Haplotype networks and mitochondrial distances}

For each analysis performed in this study, a summary of number of markers used and data type is displayed in Table 2. For each marker, haplotype networks were generated using the median-joining algorithm of Network, version 4.6.1.1 (Bandelt et al., 1999). Kimura 2-parameter (K2P) pairwise distances (Kimura, 1980) among mitochondrial lineages (or among species when considering outgroups) were calculated using MEGA v7 (Kumar et al., 2016). The within-group K2P distances were calculated in the same way.

\subsection{Species discovery: Principal Component Analysis (PCA) and Discriminant Analysis of Principal Components (DAPC)}

In order to determine the number of existing genetic groups without prior knowledge (i.e. mitochondrial lineage or geographic origin), we performed a Discriminant Analysis of Principal Components (DAPC) using the R software package adegenet 1.4-1 (Jombart et al., 2010). The DAPC is a clustering method that maximizes the between-group variance while minimizing the within-groups variance. This analysis uses genotypic information for each individual and each locus. Therefore, we converted our sequence data in genotype data using PGDspider v.2.1 (Lischer and Excoffier, 2012). Then, the minimum value of the Bayesian Information Criterion (BIC) was used to determine the optimal number of genetic clusters $\mathrm{k}$, implemented in adegenet. After that, DAPC was performed to define the clusters and visualize their relationships. It also provides membership probabilities, i.e. the per individual probability of belonging to a particular cluster. Analyses were performed including and excluding the mitochondrial marker $\mathrm{COI}$ to infer whether it significantly influenced the genetic clustering. Pairwise $\mathrm{F}_{\mathrm{ST}}$ was calculated for the six genetic clusters found with the DAPC analysis (see Results) using Genetix (Belkhir et al., 2004). In order to infer dispersal abilities and potential gene flow between allopatric clusters (C2-C3 and C5-C6; see Results), patterns of isolation by distance were investigated. Pairwise $\mathrm{F}_{\mathrm{ST}}$ among populations were used as genetic distance. Geographic distances were measured as the shortest sea distance between populations using Google Maps (https://www.google.com/maps). Mantel tests were performed using Genetix (Belkhir et al., 2004). Furthermore, genetic diversity metrics (number of segregating sites; haplotype diversity and nucleotide diversity) per cluster were calculated using DNAsp v5.10.01 (Librado and Rozas, 2009).

We then performed a PCA on the multilocus diploid genotypes using adegenet to explore the genetic relationships among individuals without constraint and without a priori knowledge on population membership. We visualized (using colors) the genetic proximity among individuals from the distinct clusters previously identified by the DAPC, but the PCA does not use this information and does not attempt to delimit divergent groups. For this reason, it can suggest incomplete separation or hybridizations between the clusters of individuals visualized by distinct colors.

\subsection{Lineage confirmation and divergence time estimates: The multi-species coalescent}

Since genetic clusters obtained after the first approach from multilocus genotypes appeared as separate genetic entities (see Results) we

Table 2

Summary of number of markers and data type for each analysis performed in this study.

\begin{tabular}{lll}
\hline Number of markers & Data type & Analysis \\
\hline 30 & sequence & Haplotype network \\
1 (COI) & Sequence & K2P distances \\
30 & multilocus genotypes & DAPC \\
30 & multilocus genotypes & PCA \\
30 & multilocus genotypes & Fo \\
30 & sequence & K2P between clusters \\
30 & sequence & BPP \\
22 & sequence & DIYABC \\
\hline
\end{tabular}




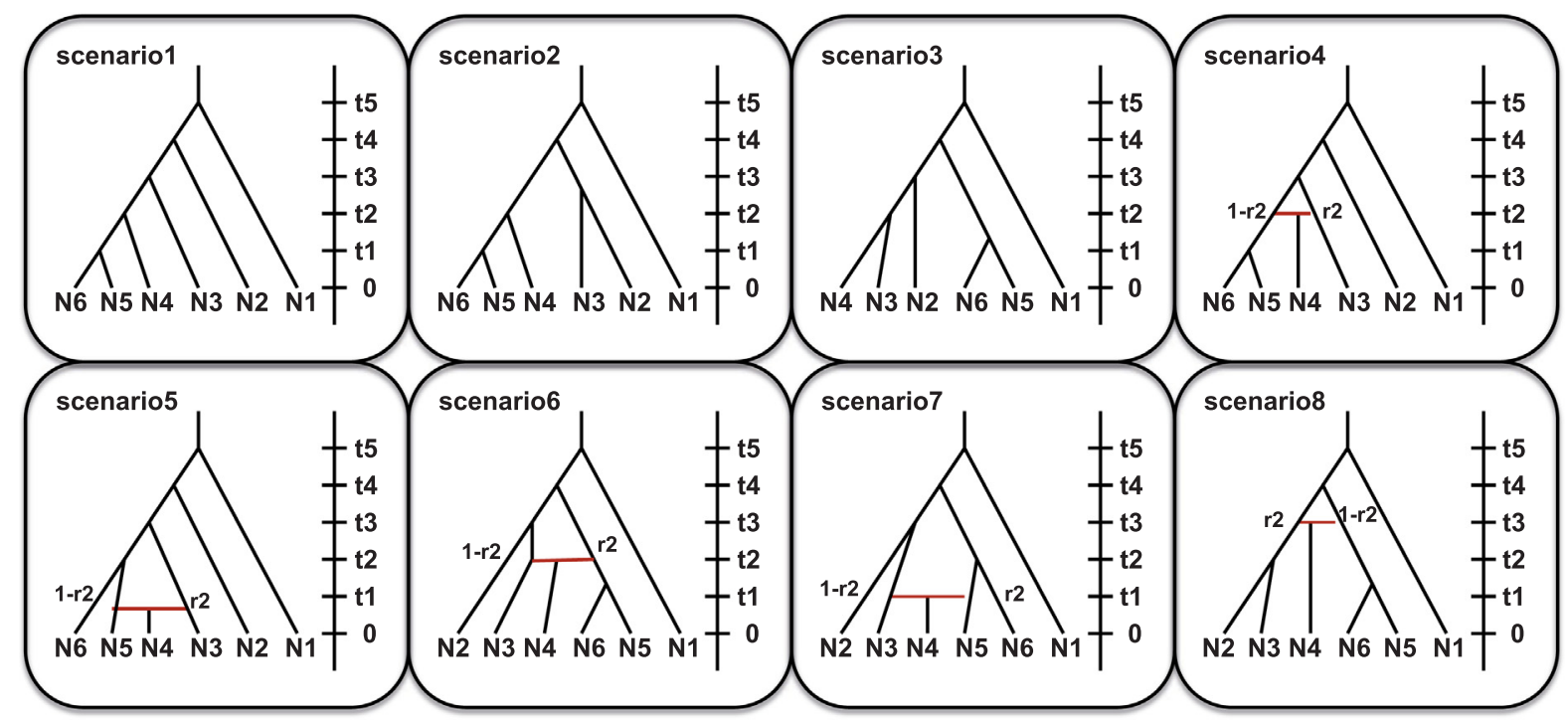

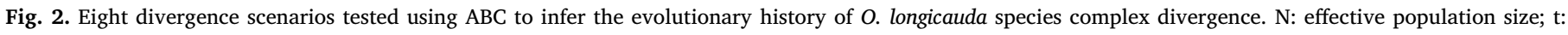
divergence time; r2: admixture rate.

considered that their relationships could be described by tree-like topologies, possibly assuming gene flow events between some clusters. Based on the genetic clusters found with DAPC, we calculated the average distance between clusters using between-group K2P distances (based on the 30 sequence markers) implemented in MEGA 6.0.5. Then, we reconstructed a phylogenetic tree based on the K2P distances between clusters, using the distance-based Neighbor-Joining method, to define a starting tree for multi-species coalescent based analyses (Fig. 2, scenario 1). Joint Bayesian species delimitation and species tree estimation was conducted using the program BPP v3.3 (analysis A11; (Rannala and Yang, 2017; Yang, 2015)). The method uses the multispecies coalescent model to compare different models of species (or lineage) delimitation (Rannala, 2015; Sukumaran \& Knowles, 2017) and species (or lineage) phylogeny in a Bayesian framework, accounting for incomplete lineage sorting due to ancestral polymorphism and gene tree-species tree conflicts (Rannala and Yang, 2013; Yang and Rannala, 2014, 2010). The population size parameters ( $\theta$ s) are assigned the gamma prior $\mathrm{G}(2,1000)$, with mean $2 / 2000=0.001$. The divergence time at the root of the species tree $(\tau 0)$ is assigned the gamma prior $\mathrm{G}(2,100)$, while the other divergence time parameters are assigned the Dirichlet prior (Yang \& Rannala, 2010: Eq. (2)). After 100,000 burnin iterations, 500,000 MCMC samples were recorded with a sample frequency of 100. Each analysis was run three times to confirm consistency between runs. Analyses were run using the full dataset and species were defined using the clusters found with DAPC.

As it was recently suggested that 'species discovery' methods may eventually not be necessary due to improvements of algorithms and computational power (Rannala, 2015), we tested the accuracy of BPP alone to discover and delimit species, using a subset of our C3 dataset for computational reasons. Indeed, as each individual is defined as a putative species in BPP, the number of different topologies to test increases more than exponentially with each additional individual. Thus, we used C3 (9 individuals) \& C5 (11 individuals) specimens from Greece (populations Agios Pavlos and Symi Island), known to represent two sympatric biological species (brooding and broadcast spawning individuals; (Weber et al., 2015, 2014)). By focusing on these sympatric populations, we ensured that approximately the same number of individuals per species was compared, across the same distributional range. A DAPC was first performed on this sub-dataset. Then, each individual was set as a single species in BPP, and three replicate analyses A11 (joint species delimitation and species tree estimation) were performed using the same parameters as previously mentioned.

\subsection{Divergence model testing using $A B C$}

Species delimitation analyses perform well to determine species number and species phylogeny, but speciation history may be more complex than a simple dichotomic process as is a species tree. We used the PCA results to identify possible cases of hybridization between groups of individuals. More specifically, the positioning of C4 (Tunisian) individuals in the PCA suggested a possible hybridization event between C3 and C5 (see Results). In addition, the C4 individuals displayed incongruent genetic signals between mitochondrial and nuclear markers previously described (Weber et al., 2015, 2014), as their mitochondrial haplotypes (COI) were closely related to the brooding species C5, whereas their nuclear genotypes (intron i51) were shared with the broadcast spawning species C3. It is noteworthy that i51 was shown to be monomorphic in the brooding species C5 and C6 (Weber et al., 2015).

Then, we used an ABC framework to test eight different models of species divergence (or scenarios) for the Ophioderma longicauda species complex, including or excluding hybridization events (Fig. 2). The posterior probability of each scenario, as well as effective sizes $(\mathrm{N})$, divergence time of each event $(\mathrm{t})$ and admixture rate $(\mathrm{r} 2)$ were estimated using ABC implemented in DIYABC v2.1.0 (Cornuet et al., 2014). Six summary statistics were used to estimate posterior probability of parameters: For the 'one sample summary statistics', the number of haplotypes, the number of segregating sites and the mean of pairwise differences were used. For the 'two-sample summary statistics', the number of haplotypes, the mean of pairwise differences (between groups) and the $\mathrm{F}_{\mathrm{ST}}$ statistics (between groups) were used. For $\mathrm{ABC}$ analyses, data from the six Ophioderma longicauda clusters were used, excluding the outgroups. In addition, eight markers were excluded due to their low amplification success in some clusters (Table S2). Three sequence groups were defined, each one with a different mutation model. The first group included 19 transcriptome-based markers, the second group included the mitochondrial marker COI and the third group included two introns (Table S2). Default priors were used in preliminary analyses $(800,000$ simulated datasets) and were then adjusted using posterior distributions and pre-evaluation verifications. When each posterior probability of parameters fell in the prior range in preliminary analyses, 8,000,000 simulated datasets were used to estimate posterior probabilities of parameters and each scenario. Model checking was performed using each available summary statistic, to verify that the parameter values of observed data belonged to posterior 
distributions.

\section{Results}

\subsection{Presence of strong incomplete lineage sorting among clusters}

Using transcriptome based markers we successfully amplified, sequenced and sorted 30 informative genetic markers (Table S2). Network analyses showed that the majority of markers displayed incomplete lineage sorting or potential signatures of introgression, except the mitochondrial marker COI and, although partially, the markers 68241_I.I, i50_II and 98699 (Fig. S1). Not only reciprocal monophyly is not observed among previously-identified species (brooding C5 and broadcast spawning C3 in Crete, (Weber et al., 2017, 2015)) but the large majority of alleles are shared among these species (Fig. S1). K2P distances among mitochondrial lineages ranged from $0.8 \%$ between L3 and L3b to $10.7 \%$ between L2 and L6 within the O. longicauda complex, whereas it ranged from $8.7 \%$ between L2 and $O$. phoenia to $11.8 \%$ between L6 and $O$. phoenia when considering the three outgroup species (Table S3).

\subsection{Multivariate analyses identify six genetic clusters}

The DAPC showed unambiguously that the optimal number of clusters (i.e. the minimal BIC value) was six (Fig. S2A). The six clusters were very distinct with nearly no overlapping in the $2 \mathrm{D}$ representation (Fig. 3A) and $100 \%$ probability of memberships for each individual (Fig. S2B). The cluster C1, including all individuals of mitochondrial lineage L6 (from Dakar and a single individual from Madeira) forms a well-defined group distant from the five other groups (Fig. 3A, Table 1). The cluster C2 includes all L5 individuals from Dakar, whereas the widely distributed broadcast-spawning cluster C3 encompasses all L1 and L5 individuals from Canary Island to Lebanon (Fig. 1, Table 1). The cluster C4 includes all L3b Tunisian individuals (Fig. 1). Finally, the brooding individuals are distributed in two different genetic clusters, incongruent with mitochondrial lineages but congruent with geography. Cluster C5 includes all L2 and L3 individuals sampled in Greece, whereas cluster C6 includes all L2 and L4 individuals sampled in Cyprus and Lebanon (Table 1). The DAPC run without the mitochondrial COI marker provided the same clustering, showing that this marker did not bias the clustering process (Fig. S3). The PCA gave essentially the same results as the DAPC, except that the higher genetic diversity of the broadcast spawners was more visible (Fig. 3B and C). In addition, C4 was even closer to C3 and C5, highlighting the capacity of PCA to explore the natural distribution of individuals and its power to detect potential hybridization events. Furthermore, one individual from Madeira assigned to the cluster $\mathrm{C} 1$ was not clustering with the other $\mathrm{C} 1$ individuals from Dakar, but was rather at mid distance between the $\mathrm{C} 1$ and C3 individuals, suggesting the presence of a potential hybrid between $\mathrm{C} 1$ and C3. Yet, further sampling would be required to properly assess this hypothesis. Therefore, we excluded this individual from further analyses. Pairwise $\mathrm{F}_{\mathrm{ST}}$ among clusters were high, ranging from 0.19 between C2 and C3 to 0.47 between C1 and C5 (Table 3). In addition, all $\mathrm{F}_{\mathrm{ST}}$ values were significant after a permutation test (Table 3).

There was no pattern of isolation by distance between C2 and C3 or within C3 (Mantel test p-value $=0.68$ ) (Fig. 4). Rather, C3 displayed no genetic structure $\left(\mathrm{F}_{\mathrm{ST}}\right.$ close to 0 ) over large geographic distances (close to $4000 \mathrm{~km}$ ). In addition, C2-C3 $\mathrm{F}_{\mathrm{ST}}$ remained close to 0.2 for distant (about $2500 \mathrm{~km}$ ) and very distant $(>6000 \mathrm{~km}$ ) comparisons. This shows that although C3 displays high dispersal abilities, it does not appear to exchange genes with C2, supporting that C2 and C3 are separated species. Contrastingly, there was a tendency for isolation by distance between the brooding clusters C5 and C6 (Mantel test pvalue $=0.15)$ (Fig. 4). This suggests that C5 and C6 may form a single very structured species. Nevertheless, as genetic diversity was higher in C6 (Fig. S4), it is possible that C5 and C6 are separated species.
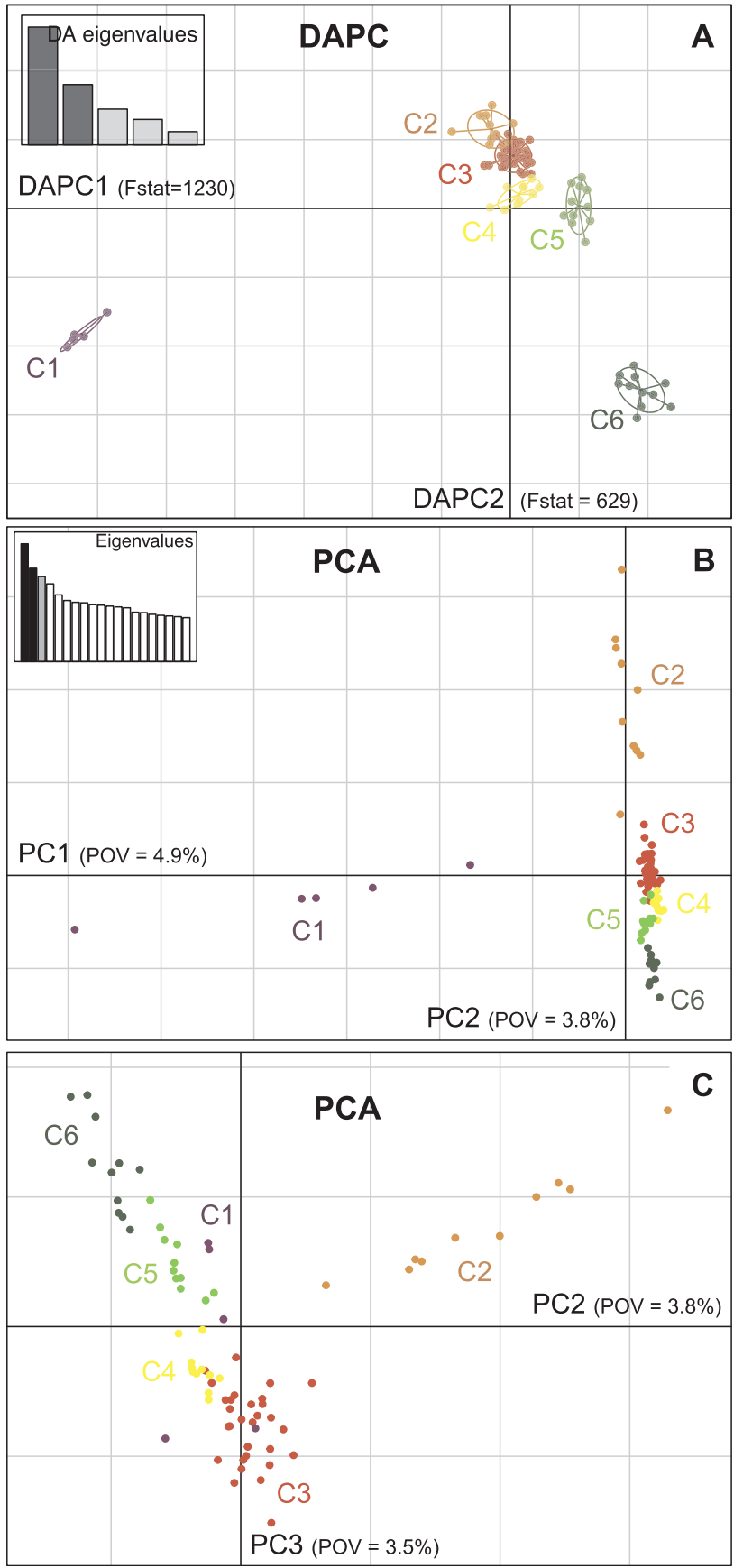

Fig. 3. (A) Results of the Discriminant Analysis of Principal Components (DAPC). Axes 1 and 2 are plotted. Fstat: ratio of between-group and withingroup variances. The six different genetic clusters are displayed. (B) Results of the Principal Components Analysis (PCA). Axes 1 and 2 are plotted. POV: proportion of variance. Individuals are colored according to their genetic cluster found in DAPC. (C) Results of the Principal Components Analysis (PCA). Axes 2 and 3 are plotted. POV: proportion of variance. Individuals are colored according to their genetic cluster found in DAPC. (For interpretation of the references to colour in this figure legend, the reader is referred to the web version of this article.)

\subsection{The multispecies coalescent provides divergence time estimates}

BPP was used to jointly perform species (or lineage) delimitation and species tree estimation using the six genetic clusters and the three outgroup species. In the three replicate analyses, the six Ophioderma genetic clusters $\mathrm{C} 1-\mathrm{C} 6$ and the three outgroups species $(O$. teres, $O$. cinerea and $O$. phoenia) were fully supported (posterior probability of 
Table 3

$\mathrm{F}_{\mathrm{ST}}$ values $(\mathrm{W} \& \mathrm{C})$ among the six genetic clusters based on 30 genetic markers. Significant $\mathrm{F}_{\mathrm{ST}}$ values after a permutation test (1000 permutations) are highlighted in bold. ${ }^{* *}: 0.001<$ P-value $<0.01$; $^{* * *}$ : P-value $<0.001$.

\begin{tabular}{|c|c|c|c|c|c|}
\hline $\mathrm{F}_{\mathrm{ST}}$ & $\mathrm{C} 2$ & $\mathrm{C} 3$ & $\mathrm{C} 4$ & C5 & C6 \\
\hline $\mathrm{C} 1$ & $0.28742^{* * * *}$ & $0.22029^{* * * *}$ & $0.43463^{\text {****}}$ & $0.47247^{* * * *}$ & $0.46308^{* * * * *}$ \\
\hline $\mathrm{C} 2$ & & $0.19154^{\text {***k}}$ & $0.35779^{\text {k*k*k}}$ & $0.37697^{* * * * *}$ & $0.38870^{\text {kiknk }}$ \\
\hline C3 & & & $0.20687^{* \text { *** }}$ & $0.32060^{\text {***** }}$ & $0.30226^{\text {k*k*k }}$ \\
\hline $\mathrm{C} 4$ & & & & $0.39383^{\text {k*k*k }}$ & $0.36829^{k * k}$ \\
\hline C5 & & & & & $0.36176^{\text {*k*kx}}$ \\
\hline
\end{tabular}

nine species $=1$; Table S4). Furthermore, the species tree of the $O$. longicauda species complex was also highly supported (C1 most ancestral, C5 \& C6 more recently diverged (Fig. S5); posterior probability $=0.92-0.99$ ), although the full topologies were different due to different placements of the three outgroups (Table S4). Using the divergence time of the geminate species $O$. teres and $O$. cinerea / $O$. phoenia (at least 2.8 mya; (Lessios, 2008)), the divergence times within the Ophioderma longicauda species complex were inferred to be at least 537,000 years ago [95\% CI: 445,223-682,795] (Table 4; Fig. S5).

It is noteworthy that the BPP analyses run on a sub-dataset of nine C3 individuals and eleven C5 individuals considering each individual as a candidate species in the starting tree gave unsupported results, with unstable numbers of estimated species and low posterior probabilities among replicate analyses (6, 3 and 2 species; Table S5). Therefore, BPP performed poorly to delimit species without a meaningful starting species tree. On the opposite, the DAPC succeeded in finding the true number of species and affecting individuals to them (Fig. S6).

\subsection{A divergence scenario supports past hybridization}

After pre-evaluation of the priors for the eight scenarios (Fig. S7A), posterior probabilities of scenarios tested with $A B C$ indicated that the most probable scenario was scenario 5 , which included hybridization between C3 and C5 (PP = 0.67; Table S6). The second most likely scenario was scenario 7, also including a hybridization event between C3 and C5 (PP = 0.26; Table S6). The remaining scenarios were not supported. After model checking of scenario 5 (Fig. S7B), parameter estimates indicated that the widespread broadcast spawning cluster C3 displayed the largest effective population size, 3 to 10 times larger than the effective population sizes of the brooding species C4, C5 and C6 (Table 5; Fig. S8). The divergence time estimates indicated that $\mathrm{C} 1$ split from other $O$. longicauda clusters about 512,000 generations ago and that the broadcasters and the brooders split about 222,000 generations ago (Table 5). The hybridization event giving rise to $\mathrm{C} 4$ was estimated about 90,000 generations ago, with a high proportion of C4 genome originating from C3 (about 86.8\%; Table 5). Overall, the divergence events of the $O$. longicauda species complex follow a pattern of West to East differentiation (Fig. 1).

\section{Discussion}

4.1. Species limits and divergence history deciphered in the O. longicauda species complex

In this study, six Ophioderma species (C1-C6) were unambiguously delimited, one of them (C4) most likely originating from the hybridization of C3 and C5. So far, only two Ophioderma species have been described in the Eastern Atlantic; Ophioderma longicauda (Bruzelius, 1805), from Dakar to Spain in the Atlantic and in the Mediterranean, and Ophioderma wahlbergii Müller \& Troschel, 1842 in South Africa, even though it was recently shown that the Mediterranean sympatric C3 \& C5 and C3 \& C6 are different biological species (Weber et al., 2015, 2014). The emergence of the Ophioderma genus occurred most likely around the Caribbean Sea, before the closing of the Panama Isthmus. Indeed, most currently recognized extant species $(26 / 28)$ of this genus thrive in this region (Stöhr et al., 2009) and the oldest confirmed Ophioderma fossil (about 10 million years old, Tortonian, early Late Miocene), is from South America (Martínez and Río, 2008). The most divergent species $\mathrm{C} 1$ occurring in West Africa split from the common ancestor of C2-C6 at least half a million years ago. Nevertheless, it is possible that the actual divergence time of the species complex is much older as partial closure events of the Panama Isthmus occurred before its final closure around 2.8 mya (e.g. sea catfishes, about 10 mya (Stange et al., 2018)). For the divergence times within O. longicauda species complex (C2-C6), we rather refer to the DIYABC estimates, as the divergence model is more accurate.

The fact that $\mathrm{C} 1$ and $\mathrm{C} 2$ were sampled in very close localities (11-17 km apart), but were yet genetically distinct, is further evidence that $\mathrm{C} 1$ and $\mathrm{C} 2$ are different biological species. Interestingly, Greef (1882) described a new species, Ophioderma guineense Greef, 1882, from West Africa (Gulf of Guinea), which was later considered conspecific with $\mathrm{O}$. longicauda, as its distinguishing morphological characters were assumed to fall within the variability of $O$. longicauda (Madsen, 1970). It is possible that this $O$. longicauda "variety" is actually the biological species we define here as C1. Yet, fresh samples from this locality are required to test this hypothesis.

Two other broadcast spawners were found, C2 in Senegal and the widespread C3 (from Canary Islands to Lebanon). These clusters most likely represent two biological species, as they do not appear to exchange genes even though C3 displays high dispersal abilities. Two

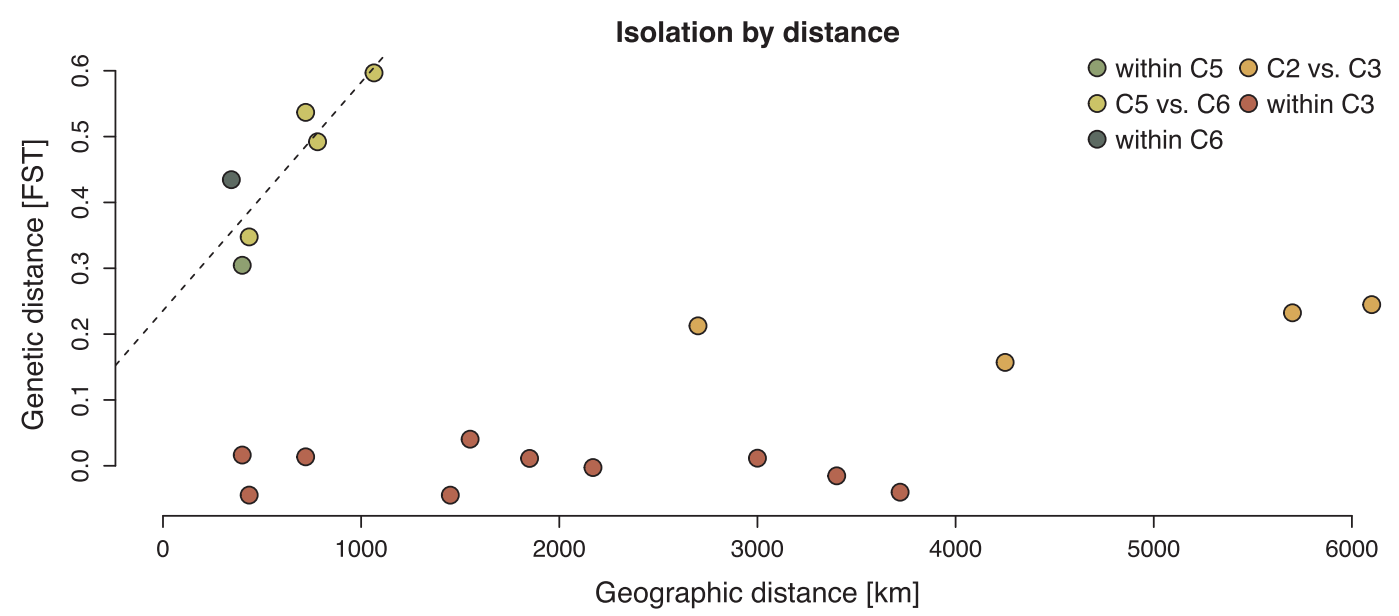

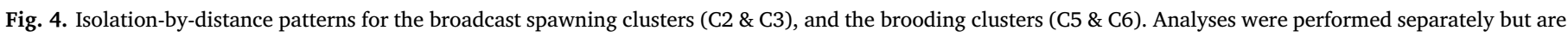
plotted on the same graph to highlight differences in dispersal abilities between broadcast spawning and brooding clusters. 
Table 4

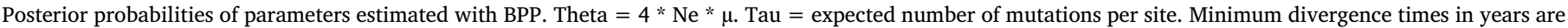

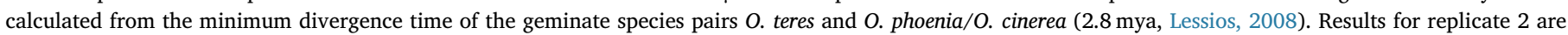
displayed. See Fig. S5 for the full species tree and the positioning of branch lengths (Tau).

\begin{tabular}{|c|c|c|c|c|c|c|c|c|}
\hline Replicate 2 & Mean & Median & Mode & $2.5 \% \mathrm{CI}$ & $97.5 \% \mathrm{CI}$ & Mode [years] & $2.5 \%$ CI [years] & 97.5\% CI [years] \\
\hline Theta_C1 & 0.005196151 & 0.005109 & 0.004971 & 0.003570775 & 0.007423225 & & & \\
\hline Theta_C2 & 0.007639499 & 0.007532 & 0.006841 & 0.005636 & 0.01023622 & & & \\
\hline Theta_C3 & 0.01682958 & 0.016739 & 0.014894 & 0.012518 & 0.02186435 & & & \\
\hline Theta_C4 & 0.002738336 & 0.002679 & 0.002408 & 0.0018 & 0.004092 & & & \\
\hline Theta_C5 & 0.001103252 & 0.001069 & 0.001277 & 0.000639775 & 0.001702 & & & \\
\hline Theta_C6 & 0.002360826 & 0.002304 & 0.002319 & 0.001494775 & 0.003635225 & & & \\
\hline Theta_Oteres & 0.004313273 & 0.004187 & 0.004004 & 0.002433 & 0.006873225 & & & \\
\hline Theta_Ophoen & 0.00736498 & 0.007178 & 0.006682 & 0.0046 & 0.01109122 & & & \\
\hline Theta_Ociner & 0.01173528 & 0.011572 & 0.011885 & 0.008069 & 0.016437 & & & \\
\hline Tau_C1.C6 & 0.01596195 & 0.015895 & 0.014907 & 0.013522 & 0.018639 & $8,920,624$ & $8,091,814$ & $11,153,922$ \\
\hline Tau_C2.C6 & 8.09527E-05 & 0.000054 & 0.00001 & 0.00001 & 0.000343 & 5984 & 5984 & 205,258 \\
\hline Tau_C3_C4_C5_C6 & 0.000131744 & 0.000113 & 0.000072 & 0.000024 & 0.000325 & 43,086 & 14,362 & 194,486 \\
\hline Tau_C4_C5_C6 & 0.000151832 & 0.000146 & 0.000156 & 0.000037 & 0.0003 & 93,353 & 22,141 & 179,526 \\
\hline Tau_C5_C6 & 0.000152483 & 0.000142 & 0.000155 & 0.00003 & 0.000341 & 92,755 & 17,953 & 204,061 \\
\hline Tau_C1 & 0.000899098 & 0.000883 & 0.000898 & 0.000744 & 0.001141 & 537,380 & 445,223 & 682,795 \\
\hline Tau_C2 & 0.000818136 & 0.000811 & 0.000804 & 0.000675 & 0.000998 & 481,128 & 403,932 & 597,222 \\
\hline Tau_C3 & 0.000686385 & 0.000688 & 0.000721 & 0.000533 & 0.000831 & 431,460 & 318,957 & 497,286 \\
\hline Tau_C4 & 0.000534565 & 0.000535 & 0.000553 & 0.000399 & 0.000685 & 330,925 & 238,769 & 409,917 \\
\hline Tau_C5 & 0.000382091 & 0.00038 & 0.00035 & 0.000247 & 0.000516 & 209,446 & 147,809 & 308,784 \\
\hline Tau_C6 & 0.000382091 & 0.00038 & 0.00035 & 0.000247 & 0.000516 & 209,446 & 147,809 & 308,784 \\
\hline tau_Oteres & 0.004415418 & 0.004374 & 0.004679 & 0.002896 & 0.006119 & $2,800,000$ & $1,733,020$ & $3,661,723$ \\
\hline Tau_Ophoen & 0.004148281 & 0.004135 & 0.003983 & 0.00274 & 0.005535 & $2,383,501$ & $1,639,667$ & $3,312,246$ \\
\hline Tau_Ociner & 0.004148281 & 0.004135 & 0.003983 & 0.00274 & 0.005535 & $2,383,501$ & $1,639,667$ & $3,312,246$ \\
\hline Tau_Ophoen_Ociner & 0.000267135 & 0.000153 & 0.000003 & 0.000005 & 0.001263225 & 1795 & 2992 & 755,937 \\
\hline Tau_Ot_Op_Oc & 0.01244562 & 0.0124385 & 0.012251 & 0.0093731 & 0.01559 & $7,331,225$ & $5,609,036$ & $9,329,344$ \\
\hline
\end{tabular}

\section{Table 5}

Posterior probability values of estimated parameters for scenario 5 by ABC. $\mathrm{N}=$ effective population size; $\mathrm{t}=$ divergence times in number of generations, see details in Fig. 3. r2 = admixture rate of C3 to C5. q025 and q975 indicate the range of $95 \%$ confidence interval.

\begin{tabular}{lllll}
\hline Genetic cluster & Parameter & mode & $2.5 \% \mathrm{CI}$ & $97.5 \% \mathrm{CI}$ \\
\hline C1 & N1 & 57,000 & 21,000 & 219,000 \\
C2 & N2 & 142,000 & 53,900 & 301,000 \\
C3 & N3 & 293,000 & 226,000 & 646,000 \\
C4 & N4 & 31,700 & 9,460 & 117,000 \\
C5 & N5 & 30,000 & 9,190 & 73,500 \\
C6 & N6 & 133,000 & 61,600 & 192,000 \\
& r2 & 0.868 & 0.469 & 0.967 \\
& t1 & 38,700 & 12,900 & 69,100 \\
& t2 & 89,100 & 46,000 & 116,000 \\
& t3 & 222,000 & 119,000 & 319,000 \\
& t4 & 368,000 & 230,000 & 475,000 \\
& t5 & 512,000 & 331,000 & 928,000 \\
\hline
\end{tabular}

clusters corresponded to brooders (C5 in Greece and C6 in Cyprus and Lebanon). As a tendency for isolation by distance was found, it is possible that C5 and C6 form a single highly structured species. The cluster C4, occurring in Tunisia, is most likely also a brooder, as it displays typical characteristics of brooders (e.g. mitochondrial lineage close to the brooding C5; small effective population size; ecological preference to low depth (Weber et al., 2014)). Gonad examinations of C4 specimens were unsuccessful to determine their reproductive strategy as sampling was performed outside the reproductive season. Yet, it is known that brooders occur in this region as brooding specimens were previously sampled in Tunisia in 1849 and 1924 (Stöhr et al., 2009). Unfortunately, molecular characterization of these ancient samples failed due to poor DNA quality. Interestingly, the most likely origin of the cluster C4 is hybridization between C3 and C5, confirming our initial hypothesis. A formal taxonomic revision of Ophioderma longicauda is in progress (Stöhr et al., in preparation). The ancestral strategy of the Ophioderma genus is broadcast spawning, as all Ophioderma from the Western Atlantic and O. longicauda C3 are broadcast spawners. Brooding evolved most likely about 222,000 generations ago in the common ancestor of C5 and C6. Unfortunately, generation time in $O$. longicauda is unknown, although it is known that after they reach sexual maturity, they reproduce once a year (broadcast spawner C3 (Fenaux, 1972); brooders C5 and C6 (Stöhr et al., 2009; Weber et al., 2014)). Interestingly, another independent evolution of brooding occurred in $O$. wahlbergii, which displays much larger and fewer young in its bursae than O. longicauda C5 and C6 (Landschoff and Griffiths, 2015).

4.2. Discrepancy between mitochondrial and nuclear histories cautions the sole use of mitochondrial data for species delimitation

Mitochondrial barcodes, such as COI, have been widely used in species delimitation and species complex discovery (e.g. Hebert et al., 2003) given the ubiquity of mitochondrial DNA, its ease of amplification and high mutation rate. Also, its reduced effective size compared to nuclear DNA allows rapid lineage sorting in recently diverged populations, culminating in reciprocal monophyly. In fact, it allowed in the first place the discovery of the $O$. longicauda species complex (Boissin et al., 2011; Stöhr et al., 2009), and it is still efficient to discover additional cryptic species, including brittle stars (Boissin et al., 2017). Nevertheless, mitochondrial lineages did not correspond to species (i.e. genetic clusters) in many cases. For instance, the cluster C3 encompasses individuals displaying the lineages L1 and L5 (4.4\% divergence). The same applied for the cluster C5 (lineages L2 and L3, 1.1\% divergence) and the cluster C6 (lineages L2 and L4, 2.5\% divergence). This is most likely the result of ancient introgression events. In contrast to nuclear DNA, mitochondrial DNA is particularly prone to both selective and introgression sweeps (Currat et al., 2008; Galtier et al., 2009; Pons et al., 2014; Toews and Brelsford, 2012; see Bronstein et al., 2016 for an example in sea urchins). Finally, selection events may be responsible for the retention of particular mitochondrial haplotypes (Ballard and Whitlock, 2004; Cheviron \& Brumfield, 2009). This study emphasizes the necessity of using nuclear markers to accurately delimit species. 


\subsection{DAPC, BPP and ABC: A potential new combination of methods for species delimitation}

Here we used three methods to delimit species in the Ophioderma longicauda species complex using 30 genetic markers, of which 25 were transcriptome-based. This is a high number of sequence markers, given that from the 28 studies presented in a review on species delimitation, only two used more than 10 genetic markers (Carstens et al., 2013). The first step was performed using DAPC clustering, based on multi-locus genotypes (i.e. the sequence information was not used, only the allele frequencies; Table 2) and revealed the presence of six distinct genetic clusters. We showed that this type of clustering approach is powerful in presence of strong incomplete lineage sorting, since diagnostic differences are not needed in order to find genetic clusters, only frequency differences. Therefore, clustering approaches are appropriate for recently diverged species. Then, we verified that these six clusters were confirmed under the MSC framework using BPP that, in addition to providing a tree and estimating the most likely number of lineages, allows the estimation of parameters such as effective population sizes and divergence times. It is noteworthy that the use of BPP alone failed to delimit species on a subset of data. Although BPP has been recently criticized to delimit genetic structure rather than species (Sukumaran and Knowles, 2017), which was not ignored by BPP's authors (Rannala 2015), we believe that species delimitation based on genetic data is accurate in the Ophioderma case. Indeed, many genetic clusters are sympatric but do not exchange genes (C1-C2; C3-C4; C3-C5; C3-C6), or are genetically isolated despite being within the range of their dispersal abilities (C2 and C3), confirming that they are actual biological species. In addition, different morphological characters were found among C1, C3 and C5 after reanalysis of several specimens (Stöhr et al., in preparation).

Finally, we propose to go one step further than discovering and delimiting species by inferring a more realistic divergence history, including hybridization, with model testing using ABC. Such methods allow the comparison of complex models including hybridization, reticulate evolution and demographic events (Roux et al., 2013). We found that the most supported scenario included a hybridization event between the broadcast spawners C3 and the brooders C5. Some additional past hybridization events may also have occurred between the divergent $\mathrm{C} 1$ and the broadcast spawner C3. Indeed, an individual sampled in Madeira displayed many common alleles with C1 (among which the mitochondrial haplotype L6), but also many common alleles with C3. Yet, due to the presence of a single potential C1-C3 hybrid, we were not able to test this hypothesis. Nevertheless, this suggests that hybridization and introgression might have been common in Ophioderma species.

A previous study (Camargo et al., 2012) tested the accuracy of BPP (Yang and Rannala, 2010), spedeSTEM (Ence and Carstens, 2011) and ABC methods (Csilléry et al., 2012) for species delimitation. Based on simulations, the authors found that BPP was overall the most accurate, $\mathrm{ABC}$ displaying an intermediate accuracy and spedeSTEM the lowest accuracy. All methods displayed lower accuracy when gene flow was incorporated, yet $\mathrm{ABC}$ displayed the lowest decrease in accuracy to delimit species. Rather than finding the overall best species delimitation method, we propose to use several consecutive methods to first find the number of distinct genetic entities, and then to estimate the divergence scenarios, therefore taking advantage of the best qualities of each method.

Albeit successful, our pipeline based on exonic amplified markers relies on pre-existing genomic resources to develop genetic markers, and a relatively small number of markers has been used, contrary to other methods such as RAD-sequencing and associated techniques that sample a more representative portion of the genome (usually thousands of loci) (Davey et al., 2011). RAD-sequencing has been successfully used to delimit species (e.g. Pante et al., 2015), yet the efficiency of this method diminished drastically with genetic distance of compared species. Indeed, Pante et al. (2015) report that $>70 \%$ of loci were lost when species displaying $0.028 \%$ of mitochondrial divergence were compared (1-2 myr divergence time) and $97 \%$ of loci were lost for species displaying $2.2 \%$ of mitochondrial divergence (9-16 myr divergence). This is expected given that the majority of RAD loci are found in non-coding DNA, which accumulates mutations faster than coding DNA. Here, we could successfully retrieve $84-100 \%$ of markers for C1-C6 (10.7\% maximum mitochondrial divergence (Table S3); divergence at least 537,000 years ago (Table 4)) and 54\% of the markers for the outgroup species $(11.8 \%$ maximum mitochondrial divergence (Table S3); divergence at least 7.3 million years ago (Table 4)), highlighting that our exon-based method performs better than RAD sequencing for distantly related species, but also allows comparing closely related species. In addition, due to their longer sequences compared to RAD loci, our method allows the analysis of haplotype networks (Fig. S1). Therefore, coding sequence markers are useful to compare simultaneously closely and distantly related species.

4.4. To circumvent the use of individual PCR amplification, and to sample a larger and most likely a more representative portion of the genome, one could use our analytic framework with exon-capture data, a method shown efficient to capture exons displaying up to $12 \%$ of sequence divergence (Hancock-Hanser et al., 2013; see Hugall et al., 2015 for exon-capture specific to brittle stars). Until now, these data have mainly been used for phylogenomic purposes (O'Hara et al., 2017, 2014) but they could as well be used for cryptic species delimitation with multilocus genotype approaches, which are powerful to detect recent genetic isolation Although 30 markers allowed us to use computationally intensive methods such as BPP and ABC, a very small part of the genome was examined. Therefore, a next step would be to test the validity of our results using a phylogenomic dataset and multilocus genotype approaches, but as well inferring a species tree in a multispecies coalescent framework (e.g. ASTRAL (Mirarab et al., 2014), MPEST (Liu et al., 2010) or SVDquartets (Chifman and Kubatko, 2014)) or in a reticulated evolution framework taking incomplete lineage sorting and hybridization into account (e.g. InferNetwork from the PhyloNet software package (Than et al., 2008); see also the recent review (Elworth et al. 2018)).

\section{Conclusion}

To conclude, the use of three distinct methods with coding sequence markers allowed comparisons at the within- and between-species levels, and bridging the gap between them. We emphasize the power of multilocus genotypes to delimit recently diverged species displaying incomplete lineage sorting and the ability of $\mathrm{ABC}$ to uncover the most realistic divergence history of a species complex. We propose that these approaches can be helpful to resolve other complex speciation histories.

\section{Data statement}

The raw Miseq reads were deposited on Dryad Digital Repository and are accessible on https://doi.org/10.5061/dryad.5ks03 (The raw data of the present study are from the same Miseq run as for the study: Weber et al., 2015).

\section{Acknowledgments}

We are very grateful to the many people who contributed to sampling of Ophioderma longicauda specimens: Helmut Zibrowius, Christos Arvanitidis, Thanos Dailianis, Elena Sarropoulou, Magdalini Christodoulou, Zined Marzouk, Didier Weber, Thi Weber and Philipp Moser. Many thanks to Francisco Alonso Solis-Marin and Harilaos Lessios for providing Ophioderma outgroup samples. We also would like to thank Laurent Abi-Rached for his advice on phylogenetic analyses, Arnaud Estoup for his advice on DIYABC and the genomic sequencing platform Genotoul (INRA, Toulouse) for the Illumina sequencing. We 
thank the support team of sciCORE (center for scientific computing, University of Basel, http://scicore.unibas.ch/) for providing access to computational resources, especially Pablo Escobar Lopez. Finally, we would like to thank two anonymous reviewers for their comments on a previous version of the manuscript.

\section{Funding}

A.A-T.W was supported by a scholarship from the French Ministry of High Education, Research and Innovation. S. S. and A. C. did not receive any specific funding for this study.

\section{Appendix A. Supplementary material}

Supplementary data to this article can be found online at https:// doi.org/10.1016/j.ympev.2018.11.014.

\section{References}

Abbott, R., Albach, D., Ansell, S., Arntzen, J.W., Baird, S.J.E., Bierne, N., Boughman, J., Brelsford, A., Buerkle, C.A., Buggs, R., Butlin, R.K., Dieckmann, U., Eroukhmanoff, F, Grill, A., Cahan, S.H., Hermansen, J.S., Hewitt, G., Hudson, A.G., Jiggins, C., Jones, J., Keller, B., Marczewski, T., Mallet, J., Martinez-Rodriguez, P., Möst, M., Mullen, S., Nichols, R., Nolte, A.W., Parisod, C., Pfennig, K., Rice, A.M., Ritchie, M.G., Seifert, B., Smadja, C.M., Stelkens, R., Szymura, J.M., Väinölä, R., Wolf, J.B.W., Zinner, D., 2013. Hybridization and speciation. J. Evol. Biol. 26, 229-246. https://doi.org/10.1111/j. 1420-9101.2012.02599.x.

Abbott, R.J., Barton, N.H., Good, J.M., 2016. Genomics of hybridization and its evolutionary consequences. Mol. Ecol. 25, 2325-2332. https://doi.org/10.1111/mec. 13685 .

Agapow, P., Bininda-Emonds, O.R.P., Crandall, K.A., Gittleman, J.L., Mace, G.M., Marshall, J.C., Purvis, A., 2004. The impact of species concept on biodiversity studies. Q. Rev. Biol. 79, 161-179. https://doi.org/10.1086/383542.

Ballard, J.W.O., Whitlock, M.C., 2004. The incomplete natural history of mitochondria Mol. Ecol. 13, 729-744. https://doi.org/10.1046/j.1365-294X.2003.02063.x.

Bandelt, H.J., Forster, P., Röhl, A., 1999. Median-joining networks for inferring in traspecific phylogenies. Mol. Biol. Evol. 16, 37-48. https://doi.org/10.1093/ oxfordjournals.molbev.a026036.

Barboza, C.A., de, M., Mattos, G., Paiva, P.C., 2015. Brittle stars from the Saint Peter and Saint Paul Archipelago: morphological and molecular data. Mar. Biodivers. Rec. 8, e16. https://doi.org/10.1017/S1755267214001511.

Baric, S., Sturmbauer, C., 1999. Ecological parallelism and cryptic species in the genus Ophiothrix derived from mitochondrial DNA sequences. Mol. Phylogenet. Evol. 11, 157-162. https://doi.org/10.1006/mpev.1998.0551.

Belkhir, K., Borsa, P., Chikhi, L., Raufaste, N., Bonhomme, F., 2004. GENETIX 4.05, Population genetics software for Windows TM. Univ. Montp. II Montp.

Bickford, D., Lohman, D.J., Sodhi, N.S., Ng, P.K.L., Meier, R., Winker, K., Ingram, K.K., Das, I., 2007. Cryptic species as a window on diversity and conservation. Trends Ecol. Evol. 22, 148-155. https://doi.org/10.1016/j.tree.2006.11.004.

Boissin, E., Féral, J.P., Chenuil, A., 2008. Defining reproductively isolated units in a cryptic and syntopic species complex using mitochondrial and nuclear markers: the brooding brittle star, Amphipholis squamata (Ophiuroidea). Mol. Ecol. 17, 1732-1744. https://doi.org/10.1111/j.1365-294X.2007.03652.x.

Boissin, E., Hoareau, T.B., Paulay, G., Bruggemann, J.H., 2017. DNA barcoding of reef brittle stars (Ophiuroidea, Echinodermata) from the southwestern Indian Ocean evolutionary hot spot of biodiversity. Ecol. Evol. https://doi.org/10.1002/ece3.3554.

Boissin, E., Stöhr, S., Chenuil, A., 2011. Did vicariance and adaptation drive cryptic speciation and evolution of brooding in Ophioderma longicauda (Echinodermata: Ophiuroidea), a common Atlanto-Mediterranean ophiuroid? Mol. Ecol. 20, 4737-4755. https://doi.org/10.1111/j.1365-294X.2011.05309.x.

Bronstein, O., Kroh, A., Haring, E., 2016. Do genes lie? Mitochondrial capture masks the Red Sea collector urchin's true identity (Echinodermata: Echinoidea: Tripneustes). Mol. Phylogenet. Evol. 104, 1-13. https://doi.org/10.1016/j.ympev.2016.07.028.

Bucklin, A., Steinke, D., Blanco-Bercial, L., 2011. DNA barcoding of marine metazoa. Ann. Rev. Mar. Sci. 3, 471-508. https://doi.org/10.1146/annurev-marine-120308 080950.

Camargo, A., Morando, M., Avila, L.J., Sites, J.W., 2012. Species delimitation with Abc and other coalescent-based methods: a test of accuracy with simulations and an empirical example with lizards of the Liolaemus Darwinii Complex (squamata: Liolaemidae). Evolution 66, 2834-2849. https://doi.org/10.1111/j.1558-5646.2012. 01640.x

Carstens, B.C., Knowles, L.L., Collins, T., 2007. Estimating species phylogeny from genetree probabilities despite incomplete lineage sorting: an example from melanoplus grasshoppers. Syst. Biol. 56, 400-411. https://doi.org/10.1080/ 10635150701405560

Carstens, B.C., Pelletier, T.A., Reid, N.M., Satler, J.D., 2013. How to fail at species delimitation. Mol. Ecol. 22, 4369-4383. https://doi.org/10.1111/mec.12413.

Chenuil, A., Hoareau, T.B., Egea, E., Penant, G., Rocher, C., Aurelle, D., Mokhtar-Jamai, K., Bishop, J.D., Boissin, E., Diaz, A., Krakau, M., Luttikhuizen, P.C., Patti, F.P., Blavet, N., Mousset, S., 2010. An efficient method to find potentially universal population genetic markers, applied to metazoans. BMC Evol. Biol. 10, 276. https:// doi.org/10.1186/1471-2148-10-276.

Cheviron, Z.A., Brumfield, R.T., 2009. Migration-selection balance and local adaptation of mitochondrial haplotypes in rufous-collared sparrows (Zonotrichia capensis) along an elevational gradient. Evolution 63, 1593-1605. https://doi.org/10.1111/j.15585646.2009.00644.x.

Chifman, J., Kubatko, L., 2014. Quartet inference from SNP data under the coalescent model. Bioinformatics 30, 3317-3324. https://doi.org/10.1093/bioinformatics/ btu530.

Cornuet, J.-M., Pudlo, P., Veyssier, J., Dehne-Garcia, A., Gautier, M., Leblois, R., Marin, J.-M., Estoup, A., 2014. DIYABC v2.0: a software to make approximate Bayesian computation inferences about population history using single nucleotide polymorphism, DNA sequence and microsatellite data. Bioinformatics 30, 1187-1189. https://doi.org/10.1093/bioinformatics/btt763.

Csilléry, K., Blum, M.G.B., Gaggiotti, O.E., François, O., 2010. Approximate Bayesian Computation (ABC) in practice. Trends Ecol. Evol. 25, 410-418. https://doi.org/10. 1016/j.tree.2010.04.001.

Csilléry, K., François, O., Blum, M.G.B., 2012. abc: an R package for approximate Bayesian computation (ABC). Methods Ecol. Evol. 3, 475-479. https://doi.org/10. 1111/j.2041-210X.2011.00179.x.

Currat, M., Ruedi, M., Petit, R.J., Excoffier, L., 2008. The hidden side of invasions: massive introgression by local genes. Evolution 62, 1908-1920. https://doi.org/10. 1111/j.1558-5646.2008.00413.x.

Davey, J.W., Hohenlohe, P.A., Etter, P.D., Boone, J.Q., Catchen, J.M., Blaxter, M.L., 2011. Genome-wide genetic marker discovery and genotyping using next-generation sequencing. Nat. Rev. Genet. 12, 499-510. https://doi.org/10.1038/nrg3012.

De Queiroz, K., 2007. Species concepts and species delimitation. Syst. Biol. 56, 879-886.

Elworth, R. L., Ogilvie, H. A., Zhu, J., Nakhleh, L., 2018. Advances in Computational Methods for Phylogenetic Networks in the Presence of Hybridization. arXiv preprint arXiv:1808.08662. https://arxiv.org/abs/1808.08662.

Ence, D.D., Carstens, B.C., 2011. SpedeSTEM: a rapid and accurate method for species delimitation. Mol. Ecol. Resour. 11, 473-480. https://doi.org/10.1111/j.1755-0998. 2010.02947.x.

Falush, D., Stephens, M., Pritchard, J.K., 2003. Inference of population structure using multilocus genotype data: linked loci and correlated allele frequencies. Genetics 164, 1567-1587.

Fenaux, L., 1972. Evolution saisonnière des gonades chez l'Ophiure Ophioderma longicauda (Retzius), Ophiuroidea. Int. Rev. Gesamten Hydrobiol. Hydrogr. 57, 257-262. https://doi.org/10.1002/iroh.19720570205.

Fujita, M.K., Leaché, A.D., Burbrink, F.T., McGuire, J.A., Moritz, C., 2012. Coalescentbased species delimitation in an integrative taxonomy. Trends Ecol. Evol. 27, 480-488. https://doi.org/10.1016/j.tree.2012.04.012.

Galtier, N., Nabholz, B., Glémin, S., Hurst, G.D.D., 2009. Mitochondrial DNA as a marker of molecular diversity: a reappraisal. Mol. Ecol. 18, 4541-4550. https://doi.org/10. 1111/j.1365-294X.2009.04380.x.

Gérard, K., Guilloton, E., Arnaud-Haond, S., Aurelle, D., Bastrop, R., Chevaldonné, P., Derycke, S., Hanel, R., Lapègue, S., Lejeusne, C., Mousset, S., Ramšak, A., Remerie, T., Viard, F., Féral, J.-P., Chenuil, A., 2013. PCR survey of 50 introns in animals: crossamplification of homologous EPIC loci in eight non-bilaterian, protostome and deuterostome phyla. Mar. Genomics 12, 1-8. https://doi.org/10.1016/j.margen.2013. 10.001 .

Greeff, R., 1882. Echinodermen beobachtet auf einer Reise nach der Guinea-Insel SaoThomé. Zool. Anz. 107, 156-159.

Hancock-Hanser, B.L., Frey, A., Leslie, M.S., Dutton, P.H., Archer, F.I., Morin, P.A., 2013 Targeted multiplex next-generation sequencing: advances in techniques of $\mathrm{mi}-$ tochondrial and nuclear DNA sequencing for population genomics. Mol. Ecol. Resour. 13, 254-268. https://doi.org/10.1111/1755-0998.12059.

Hebert, P.D.N., Ratnasingham, S., de Waard, J.R., 2003. Barcoding animal life: cytochrome c oxidase subunit 1 divergences among closely related species. Proc. R. Soc Lond. B Biol. Sci. 270, S96-S99. https://doi.org/10.1098/rsbl.2003.0025.

Hebert, P.D.N., Penton, E.H., Burns, J.M., Janzen, D.H., Hallwachs, W., 2004. Ten species in one: DNA barcoding reveals cryptic species in the neotropical skipper butterfly Astraptes fulgerator. Proc. Natl. Acad. Sci. USA 101, 14812-14817. https://doi.org/ 10.1073/pnas.0406166101.

Heimeier, D., Lavery, S., Sewell, M.A., 2010. Molecular species identification of Astrotoma agassizii from planktonic embryos: further evidence for a cryptic species complex. J. Hered. 101, 775-779. https://doi.org/10.1093/jhered/esq074.

Hoareau, T.B., Boissin, E., Paulay, G., Bruggemann, J.H., 2013. The Southwestern Indian Ocean as a potential marine evolutionary hotspot: perspectives from comparative phylogeography of reef brittle-stars. J. Biogeogr. 40, 2167-2179. https://doi.org/10. 1111/jbi.12155.

Huelsenbeck, J.P., Andolfatto, P., Huelsenbeck, E.T., 2011. Structurama: Bayesian inference of population structure. Evol. Bioinforma. Online 7, 55-59. https://doi.org/ 10.4137/EBO.S6761.

Hugall, A.F., O'Hara, T.D., Hunjan, S., Nilsen, R., Moussalli, A., 2015. An exon-capture system for the entire class Ophiuroidea. Mol. Biol. Evol. 33, 281-294.

Hunter, R.L., Halanych, K.M., 2008. Evaluating connectivity in the brooding brittle star Astrotoma agassizii across the Drake passage in the Southern Ocean. J. Hered. 99, 137-148. https://doi.org/10.1093/jhered/esm119.

Jombart, T., Devillard, S., Balloux, F., 2010. Discriminant analysis of principal components: a new method for the analysis of genetically structured populations. BMC Genet. 11, 94. https://doi.org/10.1186/1471-2156-11-94.

Kimura, M., 1980. A simple method for estimating evolutionary rates of base substitutions through comparative studies of nucleotide sequences. J. Mol. Evol. 16, 111-120. https://doi.org/10.1007/BF01731581.

Knowlton, N., 1993. Sibling species in the Sea. Annu. Rev. Ecol. Syst. 24, 189-216. 
https://doi.org/10.2307/2097177.

Kumar, S., Stecher, G., Tamura, K., 2016. MEGA7: molecular evolutionary genetics analysis Version 7.0 for bigger datasets. Mol. Biol. Evol. 33, 1870-1874. https://doi. org/10.1093/molbev/msw054.

Lamichhaney, S., Han, F., Webster, M.T., Andersson, L., Grant, B.R., Grant, P.R., 2017. Rapid hybrid speciation in Darwin's finches. Science. https://doi.org/10.1126/ science.aao4593.

Landschoff, J., Griffiths, C.L., 2015. Brooding behavior in the shallow-water brittle star Ophioderma wahlbergii. Invertebr. Biol. 134, 168-179. https://doi.org/10.1111/ivb. 12081.

Lessios, H.A., 2008. The great American schism: divergence of marine organisms after the rise of the Central American Isthmus. Annu. Rev. Ecol. Evol. Syst. 39, 63-91.

Librado, P., Rozas, J., 2009. DnaSP v5: a software for comprehensive analysis of DNA polymorphism data. Bioinformatics 25, 1451-1452. https://doi.org/10.1093/ bioinformatics/btp187.

Linnaeus, C., 1758. Systema naturæ per regna tria naturæ, secundum classes, ordines, genera, species, cum characteribus, differentiis, synonymis, locis, 10th ed. Holmiae, Stockholm.

Lischer, H.E.L., Excoffier, L., 2012. PGDSpider: an automated data conversion tool for connecting population genetics and genomics programs. Bioinformatics 28, 298-299. https://doi.org/10.1093/bioinformatics/btr642.

Liu, L., Yu, L., Edwards, S.V., 2010. A maximum pseudo-likelihood approach for estimating species trees under the coalescent model. BMC Evol. Biol. 10, 302. https:// doi.org/10.1186/1471-2148-10-302.

Lopes, J.S., Beaumont, M.A., 2010. ABC: A useful Bayesian tool for the analysis of population data. Infect. Genet. Evol MEEGID IX 10, 825-832. https://doi.org/10.1016/ j.meegid.2009.10.010.

Madsen, F.J., 1970. West African Ophiuroids. Atlantide Rep. 11, 151-243.

Martínez, S., Río, C.J.D.E.L., 2008. A new, first fossil species of. Zootaxa 52, 43-52.

Meier, J.I., Marques, D.A., Mwaiko, S., Wagner, C.E., Excoffier, L., Seehausen, O., 2017. Ancient hybridization fuels rapid cichlid fish adaptive radiations. Nat. Commun. 8, 14363. https://doi.org/10.1038/ncomms14363.

Melo-Ferreira, J., Vilela, J., Fonseca, M.M., Fonseca, D.R.R., Boursot, P., Alves, P.C., 2014. The elusive nature of adaptive mitochondrial DNA evolution of an arctic lineage prone to frequent introgression. Genome Biol. Evol. 6, 886-896. https://doi. org/10.1093/gbe/evu059.

Mirarab, S., Reaz, R., Bayzid, M.S., Zimmermann, T., Swenson, M.S., Warnow, T., 2014. ASTRAL: genome-scale coalescent-based species tree estimation. Bioinformatics 30 i541-i548. https://doi.org/10.1093/bioinformatics/btu462.

Mkare, T.K., van Vuuren, B.J., Teske, P.R., 2017. Conservation implications of significant population differentiation in an endangered estuarine seahorse. Biodivers. Conserv. 26, 1275-1293. https://doi.org/10.1007/s10531-017-1300-5.

Muths, D., Davoult, D., Gentil, F., Jollivet, D., 2006. Incomplete cryptic speciation between intertidal and subtidal morphs of Acrocnida brachiata (Echinodermata: Ophiuroidea) in the Northeast Atlantic. Mol. Ecol. 15, 3303-3318. https://doi.org/ 10.1111/j.1365-294X.2006.03000.x.

Muths, D., Jollivet, D., Gentil, F., Davoult, D., 2009. Large-scale genetic patchiness among NE Atlantic populations of the brittle star Ophiothrix fragilis. Aquat. Biol. 5, 117-132.

Naughton, K.M., O'Hara, T.D., Appleton, B., Cisternas, P.A., 2014. Antitropical distributions and species delimitation in a group of ophiocomid brittle stars (Echinodermata: Ophiuroidea: Ophiocomidae). Mol. Phylogenet. Evol. 78, 232-244. https://doi.org/ 10.1016/j.ympev.2014.05.020.

O'Hara, T.D., Hugall, A.F., Thuy, B., Moussalli, A., 2014. Phylogenomic resolution of the class Ophiuroidea unlocks a global microfossil record. Curr. Biol. 24, 1874-1879.

O'Hara, T.D., Hugall, A.F., Thuy, B., Stöhr, S., Martynov, A.V., 2017. Restructuring higher taxonomy using broad-scale phylogenomics: the living Ophiuroidea. Mol. Phylogenet. Evol. 107, 415-430.

Pante, E., Abdelkrim, J., Viricel, A., Gey, D., France, S.C., Boisselier, M.C., Samadi, S., 2015. Use of RAD sequencing for delimiting species. Heredity 114,450 . https://doi. org/10.1038/hdy.2014.105.

Penant, G., Aurelle, D., Feral, J., Chenuil, A., 2013. Planktonic larvae do not ensure gene flow in the edible sea urchin Paracentrotus lividus. Mar. Ecol. Prog. Ser. 480, 155-170. https://doi.org/10.3354/meps10194.

Pérez-Portela, R., Almada, V., Turon, X., 2013. Cryptic speciation and genetic structure of widely distributed brittle stars (Ophiuroidea) in Europe. Zool. Scr. 42, 151-169. https://doi.org/10.1111/j.1463-6409.2012.00573.x.

Pfenninger, M., Schwenk, K., 2007. Cryptic animal species are homogeneously distributed among taxa and biogeographical regions. BMC Evol. Biol. 7, 121. https://doi.org/10. 1186/1471-2148-7-121.

Pons, J.-M., Sonsthagen, S., Dove, C., Crochet, P.-A., 2014. Extensive mitochondrial introgression in North American Great Black-backed Gulls (Larus marinus) from the American Herring Gull (Larus smithsonianus) with little nuclear DNA impact. Heredity 112, 226-239. https://doi.org/10.1038/hdy.2013.98.

Puillandre, N., Lambert, A., Brouillet, S., Achaz, G., 2012. ABGD, automatic barcode gap discovery for primary species delimitation. Mol. Ecol. 21, 1864-1877. https://doi. org/10.1111/j.1365-294X.2011.05239.x.

Rannala, B., 2015. The art and science of species delimitation. Curr. Zool. 61, 846-853. https://doi.org/10.1093/czoolo/61.5.846.

Rannala, B., Yang, Z., 2017. Efficient Bayesian species tree inference under the multispecies coalescent. Syst. Biol. https://doi.org/10.1093/sysbio/syw119.

Rannala, B., Yang, Z., 2013. Improved reversible jump algorithms for Bayesian species delimitation. Genetics 194, 245-253. https://doi.org/10.1534/genetics.112.149039.

Ratnasingham, S., Hebert, P.D.N., 2007. bold: the barcode of life data system (http:// www.barcodinglife.org). Mol. Ecol. Notes 7, 355-364. https://doi.org/10.1111/j. 1471-8286.2007.01678.x.

Ribout, C., Carpentieri, C., 2013. Automated genomic DNA purification of marine organisms on the epMotion ${ }^{\circledR} 5075$ VAC from Eppendorf. Eppendorf Appl. Note 281, 1-6.

Roux, C., Tsagkogeorga, G., Bierne, N., Galtier, N., 2013. Crossing the species barrier: genomic hotspots of introgression between two highly divergent Ciona intestinalis species. Mol. Biol. Evol. 30, 1574-1587. https://doi.org/10.1093/molbev/mst066.

Schloss, P.D., Westcott, S.L., Ryabin, T., Hall, J.R., Hartmann, M., Hollister, E.B., Lesniewski, R.A., Oakley, B.B., Parks, D.H., Robinson, C.J., Sahl, J.W., Stres, B., Thallinger, G.G., Horn, D.J.V., Weber, C.F., 2009. Introducing mothur: open-source, platform-independent, community-supported software for describing and comparing microbial communities. Appl. Environ. Microbiol. 75, 7537-7541. https://doi.org/ 10.1128/AFM.01541-09.

Sponer, R., Roy, M.S., 2002. Phylogeographic analysis of the brooding brittle star Amphipholis Squamata (Echinodermata) along the coast of New Zealand reveals high cryptic genetic variation and cryptic dispersal potential. Evolution 56, 1954-1967. https://doi.org/10.1111/j.0014-3820.2002.tb00121.x.

Stange, M., Sánchez-Villagra, M.R., Salzburger, W., Matschiner, M., 2018. Bayesian divergence-time estimation with genome-wide single-nucleotide polymorphism data of sea catfishes (Ariidae) supports Miocene closure of the Panamanian Isthmus. Syst. Biol syy006.

Stöhr, S., Boissin, E., Chenuil, A., 2009. Potential cryptic speciation in Mediterranean populations of Ophioderma (Echinodermata: Ophiuroidea). Zootaxa 1-20.

Stöhr, S., Muths, D., 2010. Morphological diagnosis of the two genetic lineages of Acrocnida brachiata (Echinodermata: Ophiuroidea), with description of a new species. J. Mar. Biol. Assoc. U.K. 90, 831-843. https://doi.org/10.1017/ S0025315409990749.

Stöhr, S., Weber, A.A.-T., Boissin, E., Chenuil, A., Resolving a cryptic species complex the case of Ophioderma longicauda (Echinodermata: Ophiuroidea). In preparation.

Struck, T.H., Feder, J.L., Bendiksby, M., Birkeland, S., Cerca, J., Gusarov, V.I., Kistenich, S., Larsson, K.-H., Liow, L.H., Nowak, M.D., Stedje, B., Bachmann, L., Dimitrov, D., 2018. Finding evolutionary processes hidden in cryptic species. Trends Ecol. Evol. 33, 153-163. https://doi.org/10.1016/j.tree.2017.11.007.

Sukumaran, J., Knowles, L.L., 2017. Multispecies coalescent delimits structure, not species. Proc. Natl. Acad. Sci. 114, 1607-1612. https://doi.org/10.1073/pnas. 1607921114.

Taboada, S., Pérez-Portela, R., 2016. Contrasted phylogeographic patterns on mitochondrial DNA of shallow and deep brittle stars across the Atlantic-Mediterranean area. Sci. Rep. 6, 32425.

Than, C., Ruths, D., Nakhleh, L., 2008. PhyloNet: a software package for analyzing and reconstructing reticulate evolutionary relationships. BMC Bioinf. 9, 322. https://doi. org/10.1186/1471-2105-9-322.

Toews, D.P.L., Brelsford, A., 2012. The biogeography of mitochondrial and nuclear discordance in animals. Mol. Ecol. 21, 3907-3930. https://doi.org/10.1111/j.1365294X.2012.05664.x.

Weber, A.A.-T., Abi-Rached, L., Galtier, N., Bernard, A., Montoya-Burgos, J.I., Chenuil, A., 2017. Positive selection on sperm ion channels in a brooding brittle star: consequence of life-history traits evolution. Mol. Ecol. 26, 3744-3759.

Weber, A.A.-T., Dupont, S., Chenuil, A., 2013. Thermotolerance and regeneration in the brittle star species complex Ophioderma longicauda: a preliminary study comparing lineages and Mediterranean basins. C. R. Biol. 336, 572-581. https://doi.org/10. 1016/j.crvi.2013.10.004.

Weber, A.A.-T., Mérigot, B., Valière, S., Chenuil, A., 2015. Influence of the larval phase on connectivity: strong differences in the genetic structure of brooders and broadcasters in the Ophioderma longicauda species complex. Mol. Ecol. 24, 6080-6094. https://doi. org/10.1111/mec.13456.

Weber, A.A.-T., Stöhr, S., Chenuil, A., 2014. Genetic data, reproduction season and reproductive strategy data support the existence of biological species in Ophioderma longicauda. C. R. Biol. 337, 553-560. https://doi.org/10.1016/j.crvi.2014.07.007.

Yang, Z., 2015. The BPP program for species tree estimation and species delimitation. Curr. Zool. 61, 854-865. https://doi.org/10.1093/czoolo/61.5.854.

Yang, Z., Rannala, B., 2014. Unguided species delimitation using DNA sequence data from multiple loci. Mol. Biol. Evol. 31, 3125-3135. https://doi.org/10.1093/molbev/ msu279.

Yang, Z., Rannala, B., 2010. Bayesian species delimitation using multilocus sequence data. Proc. Natl. Acad. Sci. 107, 9264-9269. https://doi.org/10.1073/pnas. 0913022107.

Zhang, C., Zhang, D.-X., Zhu, T., Yang, Z., 2011. Evaluation of a bayesian coalescent method of species delimitation. Syst. Biol. 60, 747-761. https://doi.org/10.1093/ sysbio/syr071. 